\title{
9. The use of policy formulation tools in the venue of policy appraisal: patterns and underlying motivations
}

\author{
John R. Turnpenny, Andrew J. Jordan, \\ Camilla Adelle, Stephan Bartke, \\ Thomas Bournaris, Petrus Kautto, \\ Hanna Kuittinen, Lars Ege Larsen, \\ Christina Moulogianni, Sanna-Riikka Saarela \\ and Sabine Weiland
}

\section{INTRODUCTION}

As described in the introductory chapter, this book is concerned with the ways that actors in particular policy formulation venues gather and apply knowledge derived from using particular policy formulation tools. This chapter examines the venue of policy appraisal, which has received widespread attention from both policy formulation researchers and practitioners in the past two decades (Turnpenny et al. 2009; Adelle et al. 2012). As a formalized venue in which analysis is undertaken when formulating policy, it corresponds to the 'Internal-Official' type as defined in Chapter 1. Indeed, the use of policy appraisal is often required by law: by 2008, all 31 OECD countries had either adopted, or were in the process of adopting, a formal system of policy appraisal (OECD 2009). Policy appraisal systems may in turn harness a wide range of policy formulation tools to carry out the analysis (Carley 1980; De Ridder et al. 2007; Nilsson et al. 2008). All these elements mean that the study of policy appraisal can yield revealing insights into policy formulation as a whole, since it covers, often mandatorily, the key 'tasks' of policy formulation noted in Chapter 1, namely: characterization of the current situation; problem conceptualization; identification of policy options; assessment of potential policy options and recommending and/or proposing a specific policy design. This chapter uses policy appraisal as a window into policy formulation activities as a whole. 
Policy appraisal functions in a multitude of different ways, sometimes for very different purposes (Radaelli 2005). In investigating exactly how it does so, it is important to distinguish between (a) the political and administrative actors who establish appraisal systems, define their purpose(s) and/or monitor their operation at a high level, and (b) those actors who routinely perform the actual appraisals. We will argue that it is important to examine both sets of actors, and how they function within the wider political and institutional context of appraisal.

The operation of appraisal in practice is often investigated using one of two broad approaches: those emphasizing 'quality assessment' against particular criteria (for example, Wilkinson et al. 2004; Lee and Kirkpatrick 2006; Renda 2006; Jacob et al. 2008); and those analysing the wider influences of appraisal on policy processes, especially via the political aspects of knowledge use (for example, Nilsson et al. 2008; Hertin et al. 2009b). But there is also a third and growing strand of literature which seeks to investigate exactly how 'the initial commitment of the government to carry out the [appraisal] is an incomplete contract that can be shaped by implementation actors' (Dunlop et al. 2012, p. 40). These two aspects are interdependent and there is potentially a complex interplay of different factors which affect the ways that appraisals are ultimately carried out. The emerging view is that it is vital to study both aspects (for example, De Francesco et al. 2012). The policy implementation literature (for a review see Hill and Hupe 2009) encourages us to question how much the people undertaking appraisal enjoy significant discretion over the way in which appraisals are carried out in practice.

This chapter researches the 'incomplete contract' by focusing on the patterns of use of policy formulation tools in appraisal, and how this compares with original aspirations for tool use and for appraisal in general. Examining tool use in this venue is particularly illuminating for two main reasons. First, using tools to collect, sift and deploy knowledge constitutes a core activity in any appraisal. One might expect that analysis of even the most perfunctory of policy appraisal reports would indicate what tools (if any) had been used, by whom and for what purposes. Since generic tools are not specifically developed for any one jurisdiction, detecting whether different types of tools are used or not provides a tangible and comparable focus for examining more precisely how particular appraisals are carried out across individual jurisdictions. It may be surprising therefore that there are but a handful of studies (such as Nilsson et al. (2008)), which examine tool use patterns in only a limited number of cases. This may be especially surprising given that significant resources have been devoted to developing new tools, not least through European Commission Framework Programme funding, and there is an oft-identified 'gap' 
between tools available and tools actually used within policy appraisal (Nilsson et al. 2008). The implications for where to direct resources for tool development and deployment are therefore significant.

Second, since the application of policy formulation tools is a core activity in the venue of appraisal, it might be expected that the patterns of use will provide a critical indicator of the overall attitudes towards appraisal, both in particular jurisdictions (what might be termed jurisdiction-level motivations') and in particular policy areas and activities (or 'policylevel motivations'), and help to illuminate the nature and workings of the 'incomplete contract'. Given that appraisal systems are now so widespread and have such extensive resources devoted to them, it is especially important to understand why policymakers may want to appraise policies in the course of policy formulation activities. It is known that studying the operation of a policy instrument - of which appraisal systems are arguably an excellent example (Howlett 2011) - yields important clues about the values and meanings underlying political choices (for example, Hood 1983; Schneider and Ingram 1990; Lascoumes and Le Galés 2007; Bache 2010; Halpern 2010; Jordan et al. 2012). But what actual actions should be examined? Dunlop et al. (2012), for example, analysed more than 30 variables, including evidence of the timing of appraisals, any attempts to de-legitimize the appraisal process, and resource constraints. But this approach represents a highly resource-intensive data gathering exercise which typically yields a relatively small number of cases.

In this chapter we investigate whether studying the use of policy formulation tools nested within the broader venue of policy appraisal offers a quicker and resource efficient method for revealing both jurisdiction- and policy-level motivations. Investigating the use made of tools should in theory be relatively straightforward. After all, the guidance for bureaucrats on how to carry out appraisal often includes explicit reference and/ or encouragement to use them, particularly those with quantitative and monetizing elements. The existing literature (for example, Nilsson et al. 2008; Hertin et al. 2009a) on this topic notes that cost-benefit analysis has been promoted as an example of such a tool in some jurisdictions, such as Ireland, Denmark and the UK. More specific, and in some cases highly specialized and complex, computer model-based tools such as environmental system models have been promoted in other jurisdictions, notably the European Commission (Nilsson et al. 2008).

But systematic accounts of precisely which tools are actually used in different appraisal systems, and an exploration of what their (non-) use reveals about underlying motivations to appraise, are nonetheless still lacking. While there has been plenty of research that seeks to develop and diffuse specific policy formulation tools, or assess how appraisal systems 
have performed in practice (for example, see review by Adelle et al. 2012), there has been relatively little research on the underlying political motivations for both establishing appraisal systems and conducting individual appraisals in a particular manner (but see Radaelli (2010) and Dunlop et al. (2012)). Understanding such motivations of course helps us better understand how the policy formulation process works - specifically, the question of whether thinking about policy formulation as a set of instrumental tasks constitutes an accurate description of reality. A more in-depth understanding of motivations is also important for specifying criteria to evaluate the 'success' (or otherwise) of appraisal systems, and generate operational recommendations.

This chapter contributes to these debates by drawing on and analysing specific documentary data sources: references made to certain types of tools in official appraisal guidance, and also within the reports that are produced at the end of appraisals. More specifically, it examines the types of tools used in a sample of 325 published appraisals from across eight jurisdictions, using a detailed framework which includes a seven-fold classification of tool types. The following section sets out the methods and data sources, and briefly introduces the eight appraisal systems under study. The subsequent section presents the empirical results in three parts. First, the observed patterns of tool use at the level of individual policies, based on analysis of up to 50 policy cases per jurisdiction, are presented. Second, the observed patterns of tool use are compared with how tools are referred to in the legislation establishing the eight appraisal systems, and in any official appraisal guidance. This provides one indicator of the consistency between the stated motivations to appraise and their implementation (in other words, the incomplete contract' noted above). Third, the jurisdiction-level motivations for appraising (as expressed in general laws and administrative guidance) are compared with the observed tool use patterns, thus presenting another way of examining the 'incomplete contract' noted above. The final section summarizes the findings and suggests potential future directions for policy formulation research.

\section{UNDERSTANDING THE RELATIONSHIP BETWEEN POLICY FORMULATION TOOLS AND APPRAISAL MOTIVATIONS}

The subsequent analysis employs three principal sources of information. First, the legislation (or similar) which established the policy appraisal systems and, second, administrative guidance for completing appraisal 
(where available) in the different jurisdictions were analysed for any relevant statements about (a) the overall purpose of the appraisal system, and (b) what tools, if any, were to be used in the appraisals. Third, a documentary analysis of a sample of appraisal reports produced by policy officials was undertaken to ascertain what tools had been used. The jurisdictions selected were: Cyprus, Denmark, the European Commission, Finland, Greece, Ireland, Poland and the United Kingdom (UK). These jurisdictions were chosen for several reasons: they represent a spread of well-studied and less well-studied places; all have reasonably accessible appraisal processes and other government documents that could be studied empirically; and they represent both 'early' and 'late' adopters of appraisal systems (Adelle et al. 2012). Brief characteristics of the eight jurisdictions and their appraisal systems are given in Table 9.1.

The sampling strategy for selecting individual appraisal reports was as follows:

- Up to 50 appraisals were sampled in each jurisdiction, to give a sufficiently large sample size both within the jurisdiction and over all eight;

- Analysts began with the most recent appraisals (as of May 2011), and worked back in time, sampling across different policy areas in proportion to the number of appraisals carried out per policy field or ministry;

- If fewer than 50 appraisals were available, all the available ones were coded.

For each appraisal in each jurisdiction, instances where tool use was reported were coded using the following categories, based on the typology of De Ridder et al. (2007):

- Simple tools: including checklists, questionnaires, impact tables, process steps or similar techniques for assisting expert judgement, and qualitative assessment. 'Qualitative assessment' was taken to mean some text inside a box/matrix, in other words, something more sophisticated than a paragraph of text;

- Physical assessment tools: including life cycle analysis, and material flow analysis;

- Monetary assessment tools: cost-benefit analysis (CBA), costeffectiveness analysis, green accounting, and so on. CBA was interpreted to mean there is at least one monetized cost or benefit and not just that the subheadings 'costs' and 'benefits' were used for qualitative text. CBA was also taken to be indicated by some stated 

Table 9.1 Policy-level appraisal systems in eight jurisdictions: main
characteristics

\begin{tabular}{|c|c|}
\hline Jurisdiction & History of appraisal system \\
\hline Cyprus & $\begin{array}{l}\text { Established 2007, through a } \\
\text { standardized questionnaire } \\
\text { (revised 2011) }\end{array}$ \\
\hline Denmark & $\begin{array}{l}\text { Present form mandatory since } \\
1993 \text { (Circular from the Prime } \\
\text { Minister's office No 31/1993). } \\
\text { Current legal framework from } \\
1998 \text { (No 159/1998) }\end{array}$ \\
\hline $\begin{array}{l}\text { The EU } \\
\text { (European } \\
\text { Commission) }\end{array}$ & $\begin{array}{l}\text { Framework established } 2002 \\
\text { (CEC 2002) and introduced for } \\
\text { 'major policy proposals' in } 2003\end{array}$ \\
\hline
\end{tabular}

Finland

First obligations introduced in the 1970s (Pakarinen 2011, p. 133). Current system based on Bill Drafting Instructions (MoJ What is appraised?

No specific legal requirements to undertake appraisal. But each bill submitted to Parliament must be accompanied by an 'Objects and Reasons' report signed by the Attorney General (UNDP 2009) All government proposals to be considered in parliamentary readings must be screened, and appraisal carried out if deemed necessary (No 159/1998) Mandatory for most Commission initiatives, i.e. those included in its Work Programme (CEC 2010) Mandatory for all legislative proposals and, as far as possible, for subordinate regulations such as decrees 2006), supplemented by Impact Assessment in Legislative Drafting: Guidelines (MoJ 2008)

Greece Programme for national reform In principle, mandatory for of public administration (Politeia) all laws and regulations with in 2001 (Law 2880/2001); introduction of appraisal substantial impacts requested by Prime Minister in 2006. New law for better regulation passed by Parliament, 2012 (Law 4048/2012)

Ireland Introduced following OECD's Peer Review report (DT 2008, p. 6). Piloting took place 2004 2005 (DT 2005). Government Decision in June 2005 extended the system to cover all government departments

Mandatory for all proposals for primary legislation that involve a change to the regulatory framework, for 'significant' Statutory Instruments, and for proposals for EU Directives and 'significant' EU Regulations. Some areas where the application of appraisal not compulsory: for example, the Finance Bill, some emergency, criminal or security legislation and some tax law/regulations (DT no date, p. 4) 
Table 9.1 (continued)

\begin{tabular}{|c|c|c|}
\hline Jurisdiction & History of appraisal system & What is appraised? \\
\hline Poland & $\begin{array}{l}\text { Introduced in } 2002 \text { (Decree No } \\
49 \text { of the Council of Ministers: } \\
\text { Monitor Polski 02.13.221). } \\
\text { Modernized guidelines introduced } \\
\text { (2006) }\end{array}$ & $\begin{array}{l}\text { Mandatory for governmental } \\
\text { laws and decrees except for } \\
\text { budgetary laws, governmental } \\
\text { strategies, programmes and } \\
\text { policies }\end{array}$ \\
\hline UK & $\begin{array}{l}\text { Introduced in its more modern } \\
\text { form in } 1998 \text { under the 'better } \\
\text { regulation' and 'modernising } \\
\text { government' agenda (Hertin et al. } \\
\text { 2009b) }\end{array}$ & $\begin{array}{l}\text { Mandatory for all policy } \\
\text { proposals, including primary } \\
\text { or secondary legislation, codes } \\
\text { of practice or guidance that } \\
\text { impose or reduce costs on } \\
\text { businesses/voluntary sector } \\
\text { (BRE 2007, p. 1) }\end{array}$ \\
\hline
\end{tabular}

Source: Based on Jacob et al. (2008), Nilsson et al. (2008), Adelle et al. (2010).

quantitative impacts, in other words, that there are some numbers but not necessarily converted into monetized costs and benefits;

- Modelling tools: including economic, climate, environmental system and integrated assessment models;

- Scenario analysis: specifically, when a detailed scenario visioning exercise was carried out with a range of actors, rather than a simple statement of potential futures;

- Multi-criteria analysis: including multiple-attribute value theory;

- Stakeholder analysis tools: including consensus conferences, citizens' juries and focus groups. These were taken to have been used where specific analysis methods were employed to analyse the results of stakeholder consultations, rather than cases where consultations had simply happened (for example, web-based consultation);

- Other types: including special tests developed for specific assessment systems or policy types;

- No tools: cases where there is just qualitative text with no or very few numbers.

To maximize inter-coder reliability (and within the restrictions imposed by different languages), subsequent cross-checks were carried out. These particularly related to the boundaries between different tool types. 


\section{POLICY FORMULATION TOOLS AND APPRAISAL MOTIVATIONS IN PRACTICE}

\section{Tool Use in Practice}

Table 9.2 summarizes the findings from the analysis of the published appraisals. For each jurisdiction it includes the number of appraisal cases studied, and the average length of the appraisal reports. Some jurisdictions, such as Poland and Cyprus, yielded fewer cases as the overall number of published appraisals available was much more limited. The variable numbers of appraisals per year in each jurisdiction meant that different time periods were required to achieve the full sample size. As there was very little reported use of scenario, multi-criteria or stakeholder analysis tools in any jurisdiction, to streamline the analysis, these three were combined into the 'other tools' category.

Some jurisdictions (for example Cyprus, Finland and Greece) appear to use hardly any tools; in the cases of Greece and Finland, more than half the appraisals sampled reported no tools. In Finland, use of a standard checklist is reported to some extent, and other methods are occasionally reported, such as partial CBA, but on average the reports are extremely brief (less than three pages). While there is an appraisal procedure in Cyprus which requires a standard form to be filled in, no specific tools were reported in any of the cases analysed. Other jurisdictions (for example, Ireland, Poland and Denmark) show a large minority of cases using no tools, but there is more evidence of use of some simple and monetary assessment tools, in around half of the cases sampled. In Ireland, 39 per cent of cases reported no tools, and the rest were mostly simple and/or monetary assessment; few examples were reported of the use of any other evaluation technique, such as multi-criteria analysis. Table 9.2 shows that only 6 per cent of the Irish cases reported use of modelling tools; these were all related to building regulations. In Denmark, the reports were very brief and mainly revealed use of monetary assessment and simple tools, with some quantification. A few cases (12 per cent) mentioned modelling tools and two mentioned physical assessment - these relating mainly to environment and tax legislation. But while a wider range of tools was reported than in some other jurisdictions, a relatively large proportion (28 per cent) of cases still reported no tools used. Poland exhibited a similar pattern to Denmark, but while both countries showed mainly use of monetary assessment and simple tools with some quantification, Poland exhibited a relatively lower prevalence of monetary assessment tools. Again, in these jurisdictions, only a few reports mentioned modelling tools and/or physical assessment, and those that did related mainly to environment and tax policy. 


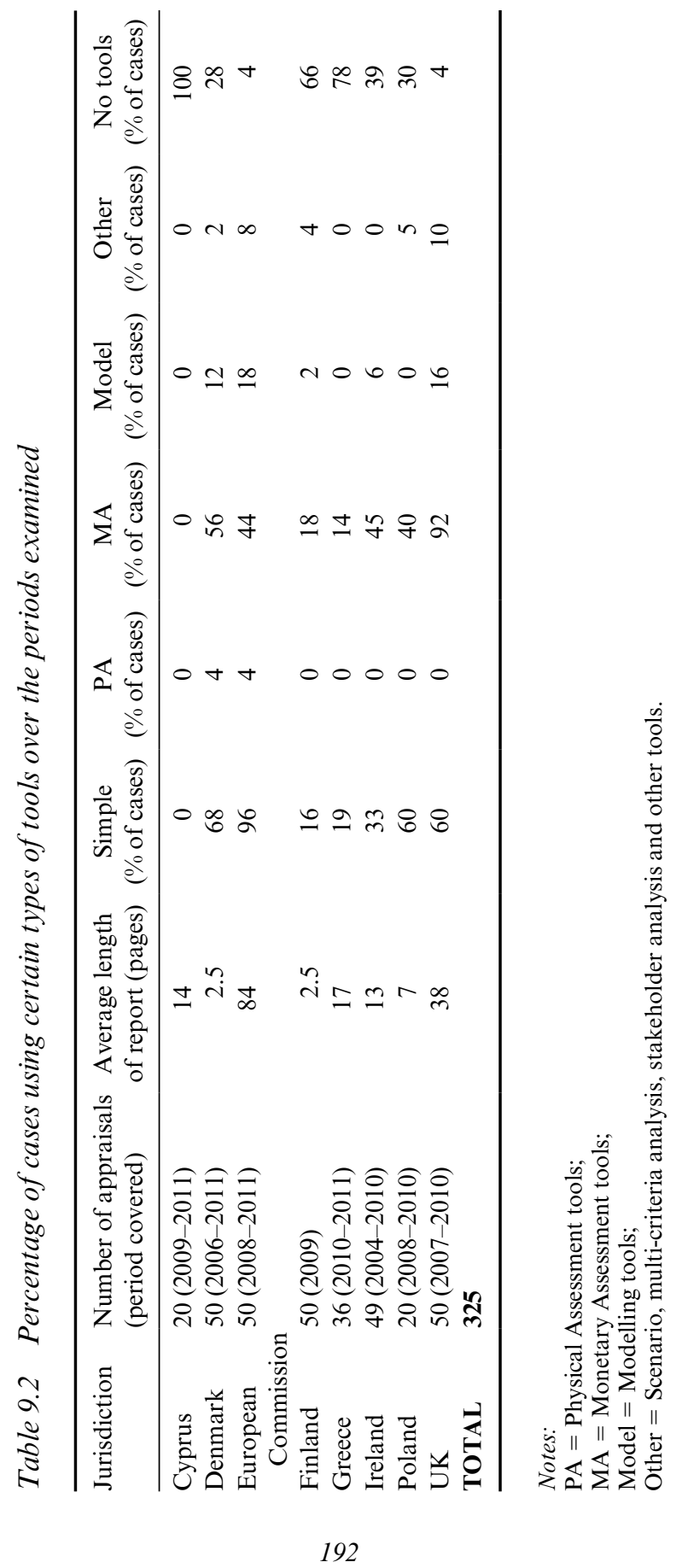

R. Turnpenny, Andrew J. Jordan, Camilla Adelle, Stephan Bartke, Thomas Bournaris, and Petrus Kautto - 9781783477043 
Conversely, the European Commission and the UK have much richer patterns of reported tool use, with only a handful of cases using no tools. In the European Commission, almost all of the cases reported use of simple tools, and just under half reported monetary assessment. There are also more cases of modelling tools being reported (about one in five cases) than in any other jurisdiction. The average length of the appraisal reports was also more than double that of any other jurisdiction. The UK, by contrast, showed greater use particularly of monetary assessment, which is mandatory in the appraisal guidelines. Analysis was mainly expressed in qualitative terms, drawing on both official and stakeholder-derived data. A few cases (16 per cent) mentioned modelling tools, and these were mainly economic models in the fields of housing, transport and pensions policy. Some such appraisals are very long (more than 200 pages) and contain much detailed analysis, but the majority are rather brief. Few appraisal reports mentioned specific tools for participatory analysis; there was often just a consultation with no additional methods employed for synthesizing the results.

\section{Tool Use Patterns: Guidance versus Practice}

We now turn to analyse the implications of the patterns shown in Table 9.2, first comparing the patterns of tool use in practice with how tools are referred to in the legislation setting up appraisal systems, and in any official guidance. As noted above, this provides one indicator of the consistency between the stated motivations behind the establishment of the appraisal system, and the implementation of appraisal.

In all the jurisdictions examined, tools were not mentioned at all in the enabling legislation. For that, one has to look at the guidance handed out to officials. For Cyprus and Greece, guidance was sparse, and limited to relatively simple tools such as a simple questionnaire (Greek Government 2009) or a procedure for consultation, and a statement of the broad aims for impact analysis of economic, social and environmental consequences (Orphanidou and Heracleous 2009). This is consistent with the minimal tool use observed in Table 9.2. Finland provides a marked contrast, since in spite of its apparently sparse use of tools in practice, its guidance mentions several different types of more sophisticated tools, such as numerical equilibrium models and econometric models, and 'expert analyses, checklists and matrices drawing from existing data, such as statistics and longitudinal environmental studies' (MoJ 2008, p. 33), as well as societal impact assessment (MoJ 2008, p. 37). A similar discrepancy between guidance and practice can be found in Poland.

For Ireland, Poland and Denmark, monetary assessment tools are 
explicitly encouraged in the guidance. In Ireland, for example, a 'formal cost-benefit analysis ... may need to be undertaken within the context of a broader multi-criteria approach' (DT 2009, p. 21). In Denmark, 'the most important examples are cost-benefit analysis and cost-effectiveness analysis' (FM 2005, p. 29), and 'it may be relevant to do an economic estimation of the distributional effects' (FM 2005, p. 8). There is also recurring advice to use short forms and lists of questions (in other words, simple tools). However, as Table 9.2 shows, monetary assessment is only reported in about half of the cases. One might deduce a rather weak commitment to using tools and/or following guidance, in these jurisdictions. In contrast, some cases are observed (if only a few) with more advanced tool use, in spite of this not being very explicitly encouraged. Ireland, for example, simply provides worked examples in the 2009 Guidelines for cases 'where the impacts may be broader than economic'.

In the case of the European Commission, a variety of tools and models for assessing impacts are presented in Annex 11 of the Commission's Guidelines (CEC 2009b, pp.61-72), including: three checklists covering key questions on economic, social and environmental impacts; a checklist for determining unknown figures (qualitatively); problem tree/ causal models (in other words, simple tools); and a section on different types of advanced models. In the main guidelines, cost-benefit analysis, cost-effectiveness analysis, and multi-criteria analysis are all introduced in detail (CEC 2009a, pp. 45 et seq.). In practice, almost all of the cases examined used simple tools, just under half used monetary assessment, and a sizeable minority used modelling tools too. Even so, this pattern still does not fully reflect the richness of the guidance.

Finally, in the UK, cost-benefit analysis is mandatory (BRE 2010), and there is online training on the Standard Cost Model to measure the administrative burden of regulation. The mandatory policy appraisal template operates like a simple tool; other simple tools are also used but are less recognized, such as various impact matrices in Specific Impact Tests. The observed pattern of tool use shows a closer correspondence with the guidelines than for other jurisdictions, while the guidance is rather modest in its espousal of tools.

\section{Tool Use Patterns and Jurisdiction-level Motivations for Appraising}

While the way tools are referred to in appraisal guidance provides one indicator of the motivations for performing appraisals, more explicit statements are often to be found in the laws establishing an appraisal system as well as the associated guidance. Table 9.3 shows the motivations appearing in these statements. 
Table 9.3 Jurisdiction-level motivations: stated

\begin{tabular}{|c|c|}
\hline Jurisdiction & $\begin{array}{l}\text { Stated motivations as described in laws and administrative } \\
\text { guidance }\end{array}$ \\
\hline Cyprus & $\begin{array}{l}\text { Norm-following, better legislation, reducing administrative } \\
\text { burden (NAP 2007) }\end{array}$ \\
\hline Denmark & $\begin{array}{l}\text { Better regulation (FM 2005, p. 7), evidence-informed decision } \\
\text { making (FM 2005, p. 13) }\end{array}$ \\
\hline European & Better regulation (CEC 2002, p. 2) \\
\hline Commission & $\begin{array}{l}\text { Improving regulatory quality (CEC 2002, p. 2; CEC 2009a, p. 6); } \\
\text { efficient regulatory environment (CEC 2002, p. 2); improving } \\
\text { consultation and communication (CEC 2002); sustainable } \\
\text { development (CEC 2002, p. 3) }\end{array}$ \\
\hline Finland & $\begin{array}{l}\text { Better regulation (MoJ 2008, p. 9); improving participation in } \\
\text { regulatory process (MoJ 2008, p. 9); improving transparency } \\
\text { (MoJ 2008, p. 10); evidence-informed decision making (MoJ } \\
\text { 2008, p. 9) }\end{array}$ \\
\hline Greece & $\begin{array}{l}\text { Better regulation, consultation, deliberation and participation } \\
\text { (Greek Prime Minister's Office 2006); Reduction of } \\
\text { Administrative Burden (Greek Government 2009) }\end{array}$ \\
\hline Ireland & $\begin{array}{l}\text { Reducing regulatory costs; evidence-based policymaking; } \\
\text { consultation (DT 2004, p. 5; DT 2009, p. 3); better regulation } \\
\text { (DT 2004) }\end{array}$ \\
\hline Poland & $\begin{array}{l}\text { Better regulation, evidence-based policymaking and reducing } \\
\text { regulatory costs (MG 2006; 2010). Also: transparency and } \\
\text { consultation (MG 2006, p.4, } 19 \text { ff); norm-following (esp. EU } \\
\text { and US) (MG 2006, p. 3) }\end{array}$ \\
\hline UK & $\begin{array}{l}\text { Reduce administrative burden; transparency/accountability } \\
\text { (Regulatory Reform Act, 2001; Legislative and Regulatory } \\
\text { Reform Act, 2006; BRE 2010; HMG 2011, p. 5); assess costs } \\
\text { and benefits (HMG 2011, p. 5) }\end{array}$ \\
\hline
\end{tabular}

The 'stated' motivations are often varied, with most jurisdictions giving several different reasons simultaneously for establishing an appraisal system. All declare an aim to improve regulatory quality, and many (for example, Cyprus, the Commission, Greece, Ireland, Poland and UK) explicitly mention reducing the costs of regulation and/or administration. Many also express a desire to improve participation in policymaking (the Commission, Finland, Greece, Ireland, Poland and UK) and others (the Commission, Finland, Poland and UK) mention improving the transparency of the policy process. A desire for appraisal to help achieve more evidence-based policymaking (expressed in various ways) is also found in many jurisdictions (Denmark, the Commission, Finland, Ireland, Poland and UK). 
Analysis of these 'stated' motivations alongside the pattern of observed tool use over a large number of appraisals is one useful indicator of the nature and extent of the 'incomplete contract'. The brevity of the appraisal reports and lack of reported tool use in some jurisdictions, especially Cyprus and Greece, in spite of commitments to better regulation and reducing administrative burdens, suggests a rather incomplete contract between high-level aspiration and policy practice. Similarly, Finland shows an evident contradiction between the publicly expressed aims to improve transparency and pursue evidence-informed decision making, and the brevity of appraisal descriptions in the government bills with respect to the appraisal process and tools used. A similar contradiction is observed in Poland, but here the reported tool use is greater. Indeed, in Poland, along with Ireland and Denmark, there are high-level commitments to goals such as reducing regulatory costs, evidence-informed policymaking, and/or improving transparency of the policy process, but the pattern of tool use emphasizing monetary assessment (albeit carried out rather patchily) suggests an unevenly completed contract, emphasizing reducing the costs of regulation as a key priority.

Tool use in the UK and European Commission displays a very different pattern; reports in these jurisdictions are longer and more detailed with respect to the tools used, especially those produced in the Commission. There is still a particular focus on monetary assessment, particularly in the UK, implying the importance of reducing regulatory costs. Commitment to administrative reform is also more evident than in other jurisdictions, as evidenced by the accessibility of comprehensive appraisal reports, and also more evidence of tools for eliciting wider participation beyond formal consultation, although these remain rather rare.

\section{CONCLUSIONS AND NEW DIRECTIONS}

This chapter has examined the operation of a number of policy formulation tools within one specific venue - policy appraisal. In doing so it has created something new - a systematic picture of precisely which tools are actually used in different appraisal systems. This significantly extends the existing literature, which has often focused on a limited number of cases and jurisdictions. The chapter has also provided a detailed mapping of appraisal guidance, which is used to shed new light on the 'incomplete contract' between stated aspiration and practice. It has illuminated one element of how policy formulation - a notoriously difficult process to observe - works in practice; a picture that challenges the conventional view 
of policy formulation as a discrete 'stage' of policymaking, encompassing an instrumental set of tasks.

A wide range of tool use patterns was observed across the eight jurisdictions studied, ranging from partial and minimal in some jurisdictions, to deeper and wider in others. This chapter has compared the tools encouraged in appraisal guidance and aggregated observed tool use patterns and investigated the extent of the consistency between guidance and practice. Several interesting patterns emerged. First, for some countries (for example, Greece and Cyprus), the guidance and the aggregated tool use patterns are rather consistent - guidance is sparse and tool use in practice appears minimal. Second, the UK and the Commission in particular revealed the opposite. In these jurisdictions, the guidance is rather detailed and prescriptive in its encouragement of different tools, and there is more evidence of such tools being used in practice than in other jurisdictions. Both these opposite cases exhibit a degree of 'completeness of contract', or consistency, between the commitment by government as expressed in guidance and the behaviour of implementation actors.

Third (and in stark contrast), other countries (such as Finland, Ireland, Poland and Denmark) show rather greater gaps between the encouragement of the guidance to use - particularly - monetary assessment tools, and a somewhat patchy use of those tools in practice. Although there may be a basic willingness to engage in appraisal activities at the highest level in these jurisdictions, for whatever reasons this is not being translated into everyday appraisal practices. This corresponds to what Dunlop et al. (2012) call 'perfunctory usage'. Several constraints have been suggested at different scales, ranging from the very micro level (such as lack of training) to the macro level (such as underlying political priorities) (Nilsson et al. 2008), including the priority given to appraisal and the results it produces, and what is seen as a proportionate analysis.

Regardless of which is important, this pattern indicates that there may be important differences between how those working at a high level in jurisdictions would like appraisal to be conducted, and the way it is performed in practice. This underlines the importance of analysing patterns within as well as across jurisdictions (for example, Dunlop et al. 2012); an issue which we explored when we compared the stated motivations for appraising at the jurisdiction level with the aggregated patterns of tool use in practice. Clearly, some aspirations are not appearing in practice. Furthermore, a wide range of stated motivations is evident, that is, jurisdictions are espousing tools for rather different purposes (although reducing the costs of regulation appears to be a dominant motivation in most jurisdictions).

It should not, of course, be assumed that tool use patterns alone identify the main motivations for subjecting new policy ideas to an appraisal, or 
that the stated motivations for appraising are necessarily the only ones. Many possible motivations have been hypothesized as to why appraisal systems have been established (Radaelli 2008; 2010). These include: increasing the rationality of the policy process to make it more evidencebased (for example, CEC 2009a; Hertin et al. 2009b); facilitating 'Better Regulation', including attempts to reduce the costs of regulation (for example, Baldwin 2005; Allio 2008; OECD 2008); enhancing political control over bureaucracies (for example, McCubbins et al. 1987; Radaelli 2008); 'modernizing' the state by introducing technocratic instruments used in other jurisdictions (for example, Radaelli 2005); improving transparency by opening up policymaking to a wider range of stakeholders (for example, Hood and Peters (2004) on the New Public Management movement; Radaelli and Meuwese 2010); and engaging in political symbolism 'to signal a political response to a perceived problem in the absence of actual policy measures' (Hertin et al. 2009b, p. 1198). Disentangling these motivations is not a trivial task, beyond simply inferring a minimal level of commitment from the fact that all OECD countries have now adopted such systems (OECD 2009), or taking at face value the stated aspirations of politicians and officials. One approach - which we have already noted - involves extensive fieldwork, including elite interviewing. Radaelli (2010), for example, undertook many interviews with political and administrative actors who established appraisal systems and/or monitored their operation at a high level in several countries. Together with an analysis of the presence or absence of enabling institutions such as quality control procedures, he presented four different 'images' of policy appraisal at the jurisdiction level: rational policymaking; political control of bureaucracy; public management reform; and symbolic politics. These were deduced using a set of indicators, including the level of decentralization of, and horizontal coordination mechanisms within, central government, and the type of political system present, as well as the implementation of guidelines and publication of appraisal reports.

To what extent do the 'stated' motivations revealed in this chapter at the jurisdiction level relate to Radaelli's analyses? And to what extent does our approach provide a simpler way of yielding similar information gathered through other studies? The answer is rather mixed. Radaelli (2008, 2010) for example, argued that Denmark has a pragmatic policymaking culture, and appraisal is rather a box-ticking exercise; political negotiation is hampered by strongly centralized control. The brevity of Danish appraisal reports indeed implies box-ticking, but there are a range of other tools used as well which indicate the potential for other motivations, such as rational analysis, at the policy level. In contrast, Radaelli argues that the UK and European Commission exhibit a stronger political control 
element, as shown in 'relationships between core executive and regulators, as well as the substantive trajectory of regulation' (Radaelli 2010). Nilsson et al. (2008, p. 347) also found, based on interviews in the UK, 'a striking discrepancy between the political desire for more evidence-based policy and the lack of formal analysis'. But this level of political control is not confirmed in our analysis.

To conclude, while the observed tool use patterns provide important and relatively swift insight, they do not replace the need for more detailed and patient empirical work including interviews. However, the observed tool use patterns do provide a useful way of identifying potential interviewees and cases for more in-depth study.

What conclusions may we draw from these findings about policy formulation (and its venues) more generally? Focusing on a venue such as appraisal, which is explicitly functionalist in its conception, and on tools which are often framed purely as a means to formulate 'better' policy, has shown starkly the complexity of policy formulation in practice. First, tools often do not appear in their textbook form. Classifying, for example, what counts as multi-criteria analysis, monetary assessment, a stakeholder analysis tool, or 'simple tools' in different cases proved particularly difficult. Second, the partial and context-specific patterns of tool use in appraisal across many cases and jurisdictions reveals both the political nature of policy formulation and the impact this has on the way that venues operate. So while policy formulation may be divided into a number of tasks to aid understanding, it is important to avoid the temptation to assume that different venues necessarily operate "with the aim of informing the design, content and effects of policymaking activities' (Chapter 1, this volume), forgetting the role of symbolism or political control, for example. So alongside any efforts to 'improve' the operation of appraisal, or to promote the use of new or amended tools, it is important to better understand why policy formulation venues operate in the way they do, and how and why this differs from a basic, that is, functionalist, understanding of policy formulation.

With this in mind, we end by identifying several interesting avenues for future research. First, the above analysis may be complemented by studies that consider other motivations. These can include the use of an appraisal system to: help depoliticize complex political issues (related to expressed desire for more evidence-based policymaking); provide political support for particular policy priorities such as subsidized agriculture or a healthier environment; foster policy learning (Radaelli 2008); or render the behaviour of policy officials more predictable (Lascoumes and Le Galés 2007) (itself related to political control or administrative reform). Arguably such motivations are revealed in tool use. Regarding motivations at the policy level, actors' motivations include some of the same as those mentioned at 
jurisdiction level, but potentially additional ones such as 'doing a good job', 'extending personal influence', 'care about the subject', 'sticking up for the policy/department'. Our analysis has examined a relatively short period of time, but it is conceivable that over a longer time span there may be shifts in motivations at both levels. Investigation of potential shifts will reveal more about the subtlety of how the 'incomplete contract' manifests itself.

A second avenue relates to the design of future research in this area. The data in this chapter are based purely on the information publicly available in written reports, which are easily accessed and provide a consistent object of study. The patterns of reporting, such as the length and availability of reports, are in and of themselves highly revealing. However, documentary information is rather limited in some countries and appraisal reports may either not exist or be too brief. The apparent absence of tools in certain countries (for example, Denmark and Finland) could be an artefact of the reporting procedures. Very brief summary appraisal reports may omit crucial details about tools which are actually used but not reported. A mixed methods approach might be more useful to explicate the underlying causes of these patterns. Indeed, mixed research designs could be envisaged which are less heavily focused on the formal actions and institutions of policy appraisal. Methods such as historical case studies, longitudinal analysis and/or process tracing (see Owens et al. 2004) could usefully elicit the perspectives of officials and other 'users' of tools within wider appraisal activities going well beyond the formal scope of appraisal, to include technical experts, consultants, scientists and think tanks. Such investigation could reveal the full extent to which those actors are driven by the jurisdiction-level motivations, and by external pressures, influences and ideas of their own.

Finally, how might the findings of this chapter help inform research on policy formulation more generally? Analysis in this chapter, for example, has been framed in terms of variations in the operation of one venue between jurisdictions. However - and building on Lowi (1972) - it would be interesting to explore whether tool use and venue operation, both sought and in practice, vary across different policy fields. Investigating the extent to which tools and venues are specific to certain types of problems and policy cases will add another dimension to the analysis. In the case of policy appraisal, while modelling and other advanced tools appear infrequently in even the most 'analytically advanced' jurisdictions, this is not to say they are not used at all. Investigating cases where individual appraisals' tool use varies significantly from the 'jurisdictional average' may yield interesting insights into what factors affect underlying motivations to appraise. For example, are supposedly more complex policy problems such as climate change more intensively appraised? 
Understanding why appraisal is being done, for whose benefit and with what effects are important for understanding not just how appraisal as a whole is evaluated, but how policy formulation works in practice, and why. A 'tools in practice' perspective offers a new and equally important perspective on much older debates in public policy and public administration, such as the political control of administrations, policy design and the evidence base of policymaking. This vibrant but relatively small sub-area has much to contribute to the mainstream of research, potentially allowing fruitful links to be formed between tool developers and different branches of public policy research and practice.

\section{ACKNOWLEDGEMENTS}

We would like to thank our funder, the FP7 Network of Excellence 'LIAISE', and the LIAISE Policy Advisory Board for their challenging and insightful comments on an earlier draft of this chapter.

\section{REFERENCES}

Adelle, C., A. Jordan and J. Turnpenny (2012), 'Proceeding in parallel or drifting apart? A systematic review of policy appraisal research and practices', Environment \& Planning C, 30, 400-414.

Adelle, C., A. Jordan, J. Turnpenny et al. (2010), A Summary of User Needs and Expectations with Regards to Impact Assessment, Deliverable 1.3 of the LIAISE Network of Excellence, European Commission Seventh Framework Contract no. 243826.

Allio, L. (2008), The Emergence of Better Regulation in the European Union. $\mathrm{PhD}$ Thesis: Kings College London.

Bache, I. (2010), 'Partnership as an EU policy instrument: a political history', West European Politics, 33, 58-74.

Baldwin, R. (2005), 'Is better regulation smarter regulation?', Public Law, Autumn, 485-511.

BRE (2007), Impact Assessment Guidance, London: Better Regulation Executive, Department for Business, Innovation and Skills.

BRE (2010), Impact Assessment Toolkit, London: Department for Business, Innovation and Skills.

Carley, M. (1980), Rational Techniques in Policy Analysis, London: Heinemann Educational Books.

CEC (2002), Communication from the Commission on Impact Assessment, COM (2002) 276, Brussels: Commission of the European Communities.

CEC (2009a), Impact Assessment Guidance, SEC (2009) 92, Brussels: Commission of the European Communities.

CEC (2009b), Impact Assessment Guidelines - Annexes, Brussels: Commission of the European Communities. 
CEC (2010), 'Commission initiatives requiring an impact assessment', retrieved from http://ec.europa.eu/governance/impact/which_com_init/which_com_init_ en.htm (accessed 22 May 2014).

De Francesco, F., C.M. Radaelli and V.E. Troeger (2012), 'Implementing regulatory innovations in Europe: the case of impact assessment', Journal of European Public Policy, 19, 491-511.

De Ridder, W., J. Turnpenny, M. Nilsson and A. Von Raggamby (2007), 'A framework for tool selection and use in integrated assessment for sustainable development', Journal of Environmental Assessment Policy and Management, 9 , 423-441.

DT (2004), Regulating Better: A Government White Paper Setting out Six Principles of Better Regulation, Dublin: Department of the Taoiseach.

DT (2005), Report on the Introduction of Regulatory Impact Analysis, Dublin: Department of the Taoiseach.

DT (2008), Regulatory Impact Assessment: An Operational Review, Dublin: Department of the Taoiseach.

DT (2009), Revised RIA Guidelines: How to Conduct a Regulatory Impact Assessment, Dublin: Department of the Taoiseach.

DT (no date), Progress Report to Government by the Better Regulation Group on Regulating Better, Dublin: Department of the Taoiseach.

Dunlop, C.A., M. Maggetti, C.M. Radaelli and D. Russel (2012), 'The many uses of regulatory impact assessment: a meta-analysis of EU and UK cases', Regulation \& Governance, 6, 23-45.

FM (2005), Vejledning om konsekvensanalyser, Copenhagen: Ministry of Finance.

Greek Government (2009), Guidelines for RIA report, Athens: General Secretariat of the Greek Government.

Greek Prime Minister's Office (2006), Circular Y190 (18 July 2006).

Halpern, C. (2010), 'Governing despite its instruments? Instrumentation in EU environmental policy', West European Politics, 33, 39-57.

Hertin, J., K. Jacob, U. Pesch and C. Pacchi (2009a), 'The production and use of knowledge in Regulatory Impact Assessment - an empirical analysis', Forest Policy and Economics, 11, 413-421.

Hertin, J., J. Turnpenny, A. Jordan, M. Nilsson, D. Russel and B. Nykvist (2009b), 'Rationalising the policy mess? Ex ante policy assessment and the utilisation of knowledge in the policy process', Environment and Planning A, 41, 1185-1200.

Hill, M. and P.L. Hupe (2009), Implementing Public Policy, London: Sage Publications.

HMG (2011), Impact Assessment Guidance: When to do an Impact Assessment, London: Her Majesty's Government.

Hood, C. (1983), The Tools of Government, London: Macmillan.

Hood, C. and G. Peters (2004), 'The middle aging of new public management: into the age of paradox?', Journal of Public Administration Research and Theory, 14, 267-282.

Howlett, M. (2011), Designing Public Policies: Principles and Instruments, Abingdon: Routledge.

Jacob, K., J. Hertin, P. Hjerp et al. (2008), Improving the Practice of Impact Assessment, EVIA (Evaluating Integrated Impact Assessments) project, European Commission Sixth Framework Programme.

Jordan, A.J., D. Benson, R. Wurzel and A.R. Zito (2012), 'Environmental policy: governing by multiple policy instruments?', in J.J. Richardson (ed.), 
Constructing a Policy State? Policy Dynamics in the EU, Oxford: Oxford University Press, pp. 104-124.

Lascoumes, P. and P. Le Galés (2007), 'Introduction: understanding public policy through its instruments - from the nature of instruments to the sociology of public policy instrumentation', Governance, 20, 1-21.

Lee, N. and C. Kirkpatrick (2006), 'Evidence-based policy-making in Europe: an evaluation of European Commission integrated impact assessments', Impact Assessment and Project Appraisal, 24, 23-33.

Lowi, T.J. (1972), 'Four systems of policy, politics, and choice', Public Administration Review, 32, 298-310.

McCubbins, M.D., R.G. Noll and B.R. Weingast (1987), 'Administrative procedures as instruments of political control', Journal of Law, Economics and Organization, 3, 243-277.

MG (2006), Guidelines for the Regulation Impact Assessment Adopted by the Council of Ministers on 10 October 2006, Warsaw: Polish Ministry of Economy.

MG (2010), Regulatory Impact Assessment, Warsaw: Polish Ministry of Economy.

MoJ (2006), Bill Drafting Instructions, Helsinki: Ministry of Justice, Finland.

MoJ (2008), Impact Assessment in Legislative Drafting: Guidelines, Helsinki: Ministry of Justice, Finland.

NAP (2007), Cyprus National Action Plan for Better Regulation, Nicosia: Ministries of Finance/Public Administration and Personnel.

Nilsson, M., A. Jordan, J. Turnpenny, J. Hertin, B. Nykvist and D. Russel (2008), 'The use and non-use of policy appraisal tools in public policy-making: an analysis of three European countries and the European Union', Policy Sciences, 41, 335-355.

OECD (2008), Building an Institutional Framework for Regulatory Impact Assessment: Guidance for Policy-Makers, Paris: Organisation for Economic Cooperation and Development.

OECD (2009), Indicators of Regulatory Management Systems, Paris: Organisation for Economic Cooperation and Development.

Orphanidou, S. and E. Heracleous (2009), Better Regulation in Cyprus Simply Explained, retrieved from http://www.better-regulation.org.cy/Portals/0/ Documents/presentation $\% 20$ for $\% 20 \mathrm{BR} \% 20$ in $\% 20$ cyprus $\% 20$ for $\% 20 \mathrm{KEBE} \% 20$ 16.3.12.pdf (accessed 24 November 2014).

Owens, S., T. Rayner and O. Bina (2004), 'New agendas for appraisal: reflections on theory, practice and research', Environment and Planning A, 36, 1943-1959.

Pakarinen, A. (2011), 'Lainvalmistelun kehittämisprojektien historia ja historiattomuus [Legislative development projects in Finland - a critical reflection]', Hallinnon Tutkimus, 30, 129-142.

Radaelli, C.M. (2005), 'Diffusion without convergence: how political context shapes the adoption of regulatory impact assessment', Journal of European Public Policy, 12, 924-943.

Radaelli, C.M. (2008), 'Evidence-based policy and political control: what does regulatory impact assessment tell us?', European Consortium for Political Research Joint Sessions Workshop on 'The Politics of Evidence-based Policymaking', Rennes, 11-16 April.

Radaelli, C.M. (2010), 'Rationality, power, management and symbols: four images of regulatory impact assessment', Scandinavian Political Studies, 33, 164-188.

Radaelli, C.M. and A.C.M. Meuwese (2010), 'Hard questions, hard solutions: 
proceduralisation through impact assessment in the EU', West European Politics, 33, 136-153.

Renda, A. (2006), Impact Assessment in the EU: The State of the Art and the Art of the State, Brussels: Centre for Policy Studies.

Schneider, A. and H. Ingram (1990), 'Behavioral assumptions of policy tools', Journal of Politics, 52, 510-529.

Turnpenny, J., C.M. Radaelli, A. Jordan and K. Jacob (2009), 'The policy and politics of policy appraisal: emerging trends and new directions', Journal of European Public Policy, 16, 640-653.

UNDP (2009), Ex-ante Policy Impact Assessment in Cyprus, UNDP.

Wilkinson, D., M. Fergusson, C. Bowyer et al. (2004), Sustainable Development in the European Commission's Integrated Impact Assessments for 2003: final report, London: Institute for European Environmental Policy. 